\title{
Enterprise IT Project Portfolio Selection Framework Based on Cloud Model $^{*}$
}

\section{Xin YANG}

Economics and Management Department, ZhongHuan Information Technology College TUT 300380, China

Ping SUN

Industrial Engineering Department, Management College TUT 300384, China

\begin{abstract}
The project portfolio selection is an important step in the process of project portfolio management, and needs to consider many interrelated factors. This paper based on enterprise strategy goal and aims at such the enterprise with characteristics of more IT projects and more complex project situation. This paper considers project's comprehensive return and proposes the specific evaluation system from aspects of finance, project delivery capacity and technical capability respectively. In this paper, the Delphi method is used to determine the weights, and the cloud model is used to convert qualitative assessment index into quantitative index to establish an effective IT project portfolio selection model. Based on project portfolio selection framework (PPSF), enterprises could choose the combined projects which conform to the enterprise strategic objectives, and further improve the enterprise's innovation efficiency and the competitive advantage. KEYWORD: IT project portfolio management; IT project portfolio selection framework; Cloud model
\end{abstract}

\section{INTRODUCTION}

With the development of computer network technology and the wide application of electronic commerce, more and more enterprises are faced with the development and implementation of IT projects. Therefore, how to improve the input and output ratio of IT projects to obtain maximum return rate about IT project has been an important subject facing by enterprise's top managers. Nowadays, in the internal environment of enterprise, it is quite common to develop and implement several projects at same time, so the single project management theory and methods are quite difficult to meet demand of multiple projects management. Therefore, project portfolio management theory provides effective methods and means for enterprises to solve these problems.

\section{SUMMARY OF PROJECT PORTFOLIO SELECTION FRAMEWORK}

For today's enterprises, the most crucial question is: in the case of limited resources, how can make enterprises to more effectively invest in new projects[1]. It is worth mentioning that most of existing theories of project portfolio selection is to select the single project based on optimal condition at first and then combine the individual project as portfolio through some way. However, a combination of many perfect individual projects is not the optimal status of project portfolio (Keeney 1987) [2]. NP Archer DF Ghasemzadeh [3] propose a detailed project portfolio selection framework base on Decision Support System, and this framework consists of three main stages: the strategic consideration of project selection stage, project evaluation stage and project portfolio selection stage, in addition, he set up the integrated project selection process for project portfolio.

\section{SUMMARY OF CLOUD MODEL THEORY}

The basic theory and concept of cloud model is proposed by $\mathrm{Li}$ Deyi academicians of China Academy of Engineering based on the traditional fuzzy set, and it is a kind of qualitative and quantitative uncertainty conversion model with the help of function thinking[4]. In the process of uncertainty reasoning, put fuzzy and random uncertainty concept integrated together, to constitute a mapping between qualitative and quantitative, and achieve the natural conversion between uncertain linguistic value and the quantitative value. It is

\footnotetext{
* Foundation item: the Project of Art Scientific Research of Tianjin (C12034)
} 
consistent with the characteristics of project evaluation index, and the IT project qualitative concepts have been converted into points of domain space, namely the cloud droplets. Every cloud droplets are random events described by probability distributions, droplets itself is also random. Therefore, the cloud model used as quantitative method about the qualitative concept with portfolio selection problems is intuitive and operable.

There are mainly three numerical characteristics in cloud model to describe risk evaluation index, namely Expected value, Entropy and Hyper entropy[5]. Expected value refers to the expectation of distribution for cloud droplets in the domain; it is the point that most represent the qualitative index, so as the sample that could most represent property of evaluation index. Entropy is an uncertainty measure of qualitative evaluation index; it is determined by both randomness and fuzziness of index. Hyper entropy refers to the thickness of cloud, and it is a measure of uncertainty of the entropy, and determined by the randomness and fuzziness of entropy.

Also, cloud model use positive cloud generator and reverse cloud generator to realize the mapping and transformation between qualitative and quantitative. Among them, algorithm of the positive cloud generator is:

Input: numerical characteristics (EX, EN, HE), the number of cloud droplets $\mathrm{n}$.

Output: $\operatorname{drop}\left(x_{i}, \mu_{i}\right), i=1,2, \ldots, n$

(1) $x_{i}=G(E x, E n)$;

(2) $\mathrm{En}_{i}=G(\mathrm{En}, \mathrm{He})$

(3) Calculate $\mu=\exp \left[-(x-E x)^{2} / 2\left(E_{n}\right)^{2}\right]$;

(4) $\mu$ become one of the generated cloud droplet.

(5) Repeat the steps until produce $\mathrm{n}$ cloud droplets that could directly express the results

Algorithm of the reverse cloud generator is:

Input: sample points $x_{i} \mathrm{i}=1,2, \ldots, \mathrm{n}$

Output: numerical characteristics to reflect qualitative concept (EX, EN, HE),

Specific algorithm steps are as follows:

(1) $\operatorname{Ex}=\operatorname{mean}\left(x_{i}\right)$;

(2) $E n=\operatorname{stdev}\left(x_{i}\right)$;

(3) $E n_{i}=\sqrt{-\frac{\left(x_{i}-E x\right)^{2}}{2 \ln \left(\mu_{i}\right)}}, H e=\operatorname{stdev}\left(E n_{i}\right)$;

(4) Calculate standard deviation for $\mathrm{E} n_{i}$ $\mathrm{He}=\operatorname{stdev}\left(E n_{i}\right)$, solving hyper entropy $\mathrm{He}$.

In The above formula, mean and stdev are the functions to calculate the mean and the standard deviation respectively.

\section{IT PROJECT PORTFOLIO SELECTION FRAMEWORK BASED ON CLOUD MODEL}

Compared with the general project, IT project has such characteristics as fast technology innovation, higher project risk, more uncertain factors etc. At present, there are many project selection and evaluation models such as: financial analysis method (including NPV, IRR etc) [6-7], integer programming (IP) method [8-9], analytic hierarchy process (AHP) [10], multifactor models [11], the fuzzy comprehensive evaluation (FCE) method [12], DEA method and so on, but these methods mainly focus on securities investment, scientific research and technology projects, construction and other fields, so little application in IT information technology area.

Therefore, this paper is based on the enterprise strategic goal to consider comprehensive return of IT project in three aspects of finance position, project delivery capacity and technical capability; it proposes evaluation index system and use Delphi method to determine factor weights and using cloud model and cloud generator to convert qualitative evaluation index into quantitative evaluation index system, finally establish effective IT project portfolio selection framework. The construction of IT project portfolio selection method as shown in figure 1 .

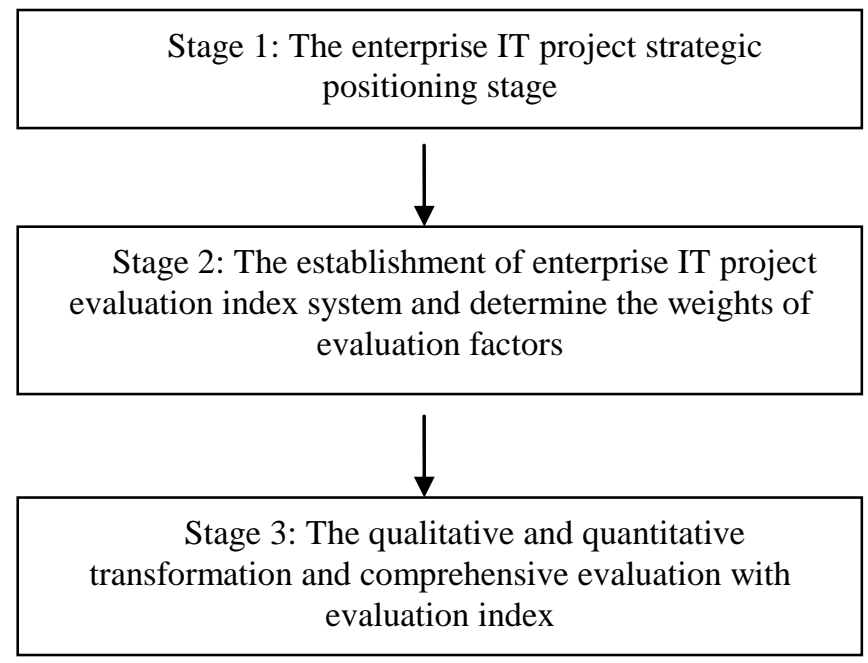

Figure 1: IT Project Portfolio Selection Framework

\section{ESTABLISHMENT OF PROJECT PORTFOLIO SELECTION FRAMEWORK}

\subsection{The Enterprise Strategic Positioning Stage}

The first content of project portfolio selection is to identify the project, determine whether these projects are consistent with the company's strategic direction, namely making initial identification and screening before thorough analysis. Because in this stage the key consideration is whether the implementation of IT project in accordance with the enterprise strategic goal, so we could establish evaluation index system 
based on enterprise strategic goal, and the index system can be used to evaluation two aspects of fitness with enterprise strategic goal and influence on enterprise strategy. We establish two secondary indexes followed by first grade index. Evaluation of the existing IT projection is according to established index system by Delphi method, if a project is inconsistent with enterprise strategic goal it should be timely terminated.

\subsection{Establishment and Implementation of Project Portfolio Selection Framework}

The comprehensive return of project can be depicted and evaluated by some indexes. Searching through the analysis of some existing results at home and abroad with combining the IT project's characteristics, this paper concluded that we could describe the main factors that impact project return by three aspects of the financial position, project delivery capacity and technical capability.

(1) Financial Position. Financial data is the direct embodiment of project income, so the financial position index is an important factor in project selection. Financial measure including project target return rate, return on investment, net present value, investment recovery period etc., and the evaluation standard could set a certain threshold based on the actual situation of the enterprises themselves.

(2) Project Delivery Capacity. Project delivery index reflects the ability of enterprises to the successful delivery an IT project. The important content of project management is to control the schedule, quality, cost, risk and ensure that the project can be completed on time and with high quality. In order to improve the success rate of IT project implementation, it is necessary to fully assess the various influence factors of IT project which delivery in the IT project selection, including the project cost, project duration, project scale, complexity, and the availability of resources.

(3) Technical capacity. With the pace of globalization, the development of information technology and the change also will be accelerated, and the influence on implementation of enterprise IT project is also more and more large. Technical features of IT project are very strong, and the technical risk is also large. The complexity and uncertainty of technology will affect the IT project decision.

After refining the evaluation index mentioned above, we could constitute project return evaluation system (as shown in table 1) including 3 first grade indexes and 16 secondary grade indexes. In addition, considering the expert's opinions, experience and knowledge; the evaluation standard could be set as $\mathrm{U}=\{$ Perfect, Good, Normal, Bad, Worst $\}$ with corresponding to the experience and knowledge of experts, expressed as fuzzy language value.
These five qualitative concept in evaluation set $\mathrm{V}=\left\{v_{1}, v_{2}, v_{3}, v_{4}, v_{5}\right\}, v_{i}=C\left(E_{X i}, E_{N i}, H_{E i}\right)$, using the method of one-dimensional normal cloud.

Table 1: Evaluation System of IT Project Return

\begin{tabular}{|c|c|c|c|}
\hline $\begin{array}{l}\text { First Class } \\
\text { Index }\end{array}$ & Weights & Second Class Index & Weights \\
\hline \multirow{4}{*}{$\begin{array}{l}\text { Financial } \\
\text { Position }\end{array}$} & \multirow{4}{*}{$\mathrm{p}_{1}$} & Return Rate & $\mathrm{w}_{1}$ \\
\hline & & Investment Return Rate & $\mathrm{w}_{2}$ \\
\hline & & NPV & $\mathrm{w}_{3}$ \\
\hline & & Recovery Period & $\mathrm{w}_{4}$ \\
\hline \multirow{7}{*}{$\begin{array}{l}\text { Project } \\
\text { Delivery } \\
\text { Capacity }\end{array}$} & \multirow{7}{*}{$\mathrm{p}_{2}$} & Project Cost & $\mathrm{w}_{5}$ \\
\hline & & Project Duration & $\mathrm{w}_{6}$ \\
\hline & & Project Scale & $\mathrm{w}_{7}$ \\
\hline & & Project Complexity & $\mathrm{w}_{8}$ \\
\hline & & Resource Availability & $\mathrm{w}_{9}$ \\
\hline & & $\begin{array}{l}\text { Project management and } \\
\text { organizational skills }\end{array}$ & $\mathrm{w}_{10}$ \\
\hline & & $\begin{array}{l}\text { The possibility of project } \\
\text { success }\end{array}$ & $\mathrm{w}_{11}$ \\
\hline \multirow{5}{*}{$\begin{array}{l}\text { Technical } \\
\text { Capacity }\end{array}$} & \multirow{5}{*}{$\mathrm{p}_{3}$} & Technical complexity & $\mathrm{w}_{12}$ \\
\hline & & Technology uncertainty & $\mathrm{w}_{13}$ \\
\hline & & $\begin{array}{l}\text { The level of technical } \\
\text { personnel }\end{array}$ & $\mathrm{w}_{14}$ \\
\hline & & $\begin{array}{l}\text { The system is dependent } \\
\text { on another system }\end{array}$ & $\mathrm{w}_{15}$ \\
\hline & & $\begin{array}{l}\text { Availability of necessary } \\
\text { technology }\end{array}$ & $\mathrm{w}_{16}$ \\
\hline
\end{tabular}

\subsection{Qualitative and Quantitative Transformation and Comprehensive Evaluation}

Using the positive cloud generator transforms the qualitative index layer into quantitative index layer, then use numerical characteristics of reverse cloud generator and generate could chart of evaluation index by positive could generator (as shown in Figure. 2). Continue to repeat the calculation method above till get satisfied could chart and value. Thus the result can be drawn as well as the quantitative value of each evaluated index.

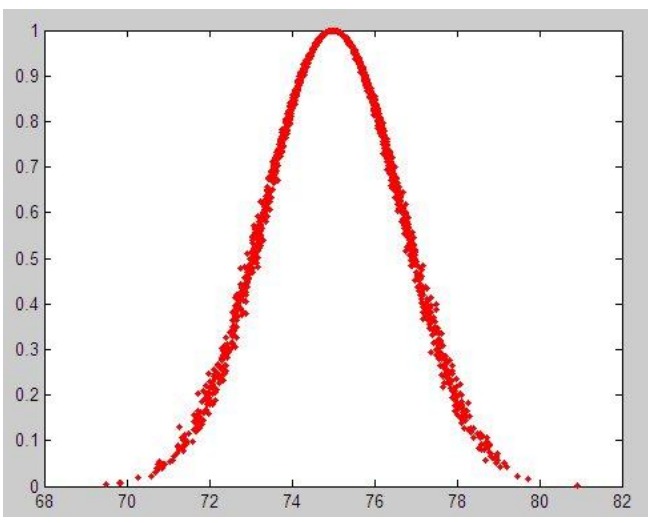

Figure 2 Cloud Chart 


\section{SUMMARY}

For the evaluation of enterprise IT project, although it is fuzzy on the surface but the essence could be quantified calculation because the establishment of a complex system is usually the cross question of the fuzziness and randomness. This paper improves the method of IT project portfolio selection using cloud model technology, and it has some practical significances.

\section{REFERENCES}

[1] Baker, N.R. R\&D project selection models: An assessment. IEEE Transactions on Engineering Management EM21:165-170(1974).

[2] Keeney, R.L (1992) Value-focused Thinking. Cambridge, MA: Harvard University Press.

[3] F. Ghasemzadeh, N.P. Archer, Project portfolio selection through decision support. Decision Support system, 2000(29):73-88.

[4] Li Dan. A. Multi attribute decision making system based on cloud model. Heilong jiang: Heilongjiang Institute of Science and Technology, 2010.

[5] Kaichang D, Deyi L, Deren L. Knowledge representation and discovery in spatial databases based on cloud theory. International Archives of Photogrammetric and Remote Sensing, 1998, 32 (3/1):544-555.

[6] Hou Ronghua, Weng Ling Further discussion on NPV and PR index in investment project evaluation Technology and Economy Industry 1995, 14 (3): 36-36.

[7] Deng Mingran, Wang Hongming, Wang Hongwei The Discounted Cash Flow Approach and Application in Investment Finance Evaluation of Project Journal of Wuhan University of Technology, 2002, 24(4):77-80.

[8] Li Chengbiao, Niu Yonglan, Xu Dingan Project Group of Goal Programming Model of Choice Industrial Technology Economics, 1996, 15(3):81-82.

[9] Shi Dawei, Jin Ruiling The Project Choice of Goal Programming Method Journal of Shanghai university of science and technology, 2000, 22(2):132-136.

[10] Chen Xuezhong, Li Guanghong, Wang LiHierarchical analysis model of investment project selection Journal of shandong institute of building materials, 2000, 14(2):152155.

[11] He Jianming, Hao Jinliang Nonlinear because of the need to input and output model research and application Chinese Journal of Management Science, 1994, (3): 24-29.

[12] Song Yaxin, Chen Jinyun, Wu Xiaoping Fuzzy multiobjective constraint investment project selection model System Engineering Theory and Practice, 2002, (5): 115119. 